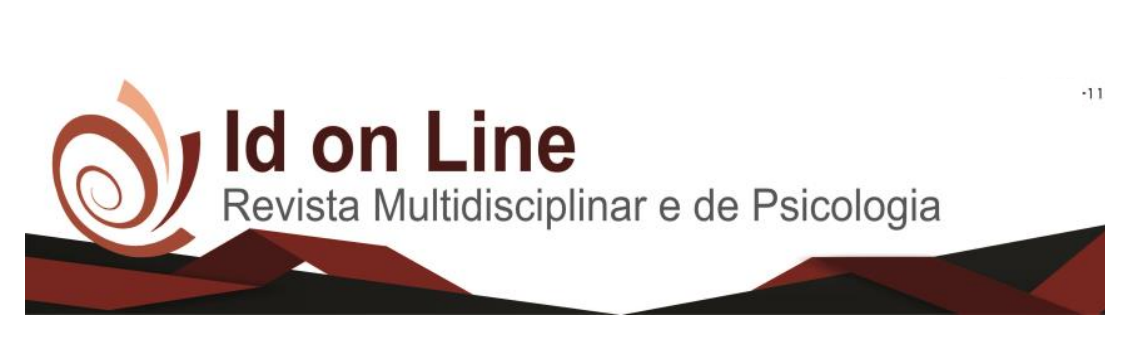

DOI: 10.14295/idonline.v13i46.2015

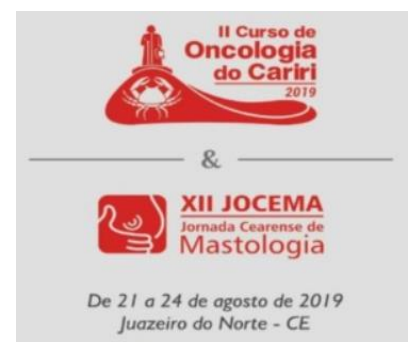

Resumo

\title{
DOENÇA PERIODONTAL E O RISCO DE CÂNCER: REVISÃO SISTEMÁTICA
}

\author{
Antonio Gean Oliveira de Alencar ${ }^{1}$, Bruna Lira da Silva Santos ${ }^{1}$, Caroline Reis França ${ }^{1}$, \\ Dália Thalya Alencar de Melo ${ }^{1}$, Lamartha Janinny Alencar Piancó ${ }^{1}$, Karine Figueredo da Costa ${ }^{2}$
}

\begin{abstract}
Introdução: A doença periodontal é a infecção polimicrobiana e inflamatória crônica, que por meio da destruição dos tecidos periodontais de sustentação, em casos sem tratamento pode resultar na perda do elemento dental. Evidências científicas mostram um aumento no risco de vários tipos de câncer em pacientes com periodontite. A inflamação sistêmica associada à periodontite, a desregulação imunológica, a invasão de bactérias patogênicas na circulação sistêmica ou a formação de carcinógenos por bactérias estão entre os mecanismos de uma possível associação. Objetivo: Esclarecer uma provável conexão entre as doenças periodontais e o câncer, bem como explicar possíveis equívocos sobre influência de fatores de risco. Metodologia: A investigação foi feita na base de dados da PubMed. Utilizando as palavras-chave: Câncer, doença periodontal, inflamação, fatores de risco. Foram selecionados artigos do tipo revisões sistemáticas avaliadas, a partir do ano 2000. Resultados: Foram encontrados inicialmente 178 artigos, sendo analisados os resumos de 20, dos quais, 15 foram lidos por completo. Em seguida, 4 textos foram selecionados para análise final, utilizando ajuste para fatores de risco. Conclusão: A literatura revelou uma relação significativa entre as doenças periodontais e o processo carcinogênico, independentemente da influência de outros fatores de risco, porém os estudos foram inconclusivos, onde necessita-se de mais exploração sobre essa questão.
\end{abstract}

Palavras-Chave: Câncer. Doença Periodontal. Inflamação. Fatores de Risco.

\section{Referências}

CORBELlA, Stefano; VERONESI, Paolo; GALIMBERTI, Viviana; WEINSTEIN, Roberto; DEL FABBRO, Massimo; FRANCETTI, Luca. Is periodontitis a risk indicator for cancer? A metaanalysis. PloS one, v. 13, n. 4, p. e0195683, 2018.

HOARE, Anilei; SOTO, Cristopher; ROJAS-CELIS, Victoria; BRAVO, Denisse. Chronic Inflammation as a Link between Periodontitis and Carcinogenesis. Mediators of inflammation, v. 2019, 2019.

MICHAUD, Dominique S; FU, Zhuxuan; SHI, Jian; CHUNG, Mei. Periodontal disease, tooth loss, and cancer risk. Epidemiologic reviews, v. 39, n. 1, p. 49-58, 2017.

SFREDDO, Camila Silveira; MAIER, Juliana; MOREIRA, Carlos Heitor Cunha. CONDIÇÃO PERIODONTAL E CÂNCER-UMA REVISÃO DE LITERATURA. Braz J Periodontol-March, v. 27, n. $01,2017$.

\footnotetext{
${ }^{1}$ Graduando em Odontologia, Universidade Doutor Leão Sampaio - UNILEÃO, Juazeiro do Norte, CE, Brasil;

${ }^{2}$ Mestre em Odontologia pela Universidade Estadual do Oeste do Paraná, UNIOESTE, Brasil. Professora do Curso de Odontologia, Universidade Doutor Leão Sampaio - UNILEÃO, Juazeiro do Norte, CE, Brasil.

Autor correspondente: E-mail para contato: geanalencar_rg.gt@hotmail.com
} 